\title{
Family relationships in childhood and common psychiatric disorders in later life: systematic review of prospective studies
}

Scott Weich, Jacoby Patterson, Richard Shaw and Sarah Stewart-Brown

\section{Background}

Most evidence for associations between childhood adversity and adult mental illness is retrospective.

\section{Aims \\ To evaluate prospective evidence of associations between poor parent-child relationships and common psychiatric disorders in later life.}

\section{Method}

Systematic review of studies published between 1970 and 2008 including: (a) more than 100 participants; (b) measures of relationships in the home during childhood; (c) at least 10 years between assessment of exposures; and (d) measures of anxiety, depression, suicide, suicidal ideation or post-traumatic stress disorder (PTSD). Analysis was by narrative synthesis.

\section{Results}

Twenty-three papers were identified reporting data from 16 cohorts. Abusive relationships predicted depression, anxiety and PTSD. Maternal emotional unavailability in early life predicted suicide attempts in adolescence. Results of studies investigating less severe relationship problems were suggestive but not conclusive of causal association, due partly to methodological heterogeneity.

\section{Conclusions}

Given the prevalence and disabling nature of common psychiatric problems, these studies highlight the need to minimise harm associated with dysfunctional parent-child relationships.

\section{Declaration of interest}

None.
Impaired emotional and social development in childhood is a precursor to poor mental health in adulthood, ${ }^{1,2}$ and may be determined in part by relationships in the home. ${ }^{3-5}$ These relationships are amenable to intervention and could represent an important area for intervention ${ }^{6,7}$ in the promotion of mental health and the prevention of mental illness. Several cross-sectional studies, employing retrospective recall, have suggested that relationships during childhood are associated with mental health outcomes in later life including depression, anxiety and selfharm. ${ }^{8-10}$ This type of research is prone to recall bias and reverse causality, and provides only weak evidence of causality. We therefore reviewed large ( $>100$ participants) longitudinal studies of 10 or more years' duration with prospective data on relationships in the home during childhood (parent-parent or parent-child) and measures of common psychiatric disorders in adulthood.

\section{Method}

\section{Data sources}

Medline, PsycINFO and Sociological Abstracts were searched for articles published in English between 1 January 1970 and 29 February 2008.

\section{Search terms}

Potential search terms were identified from the literature on relationships in the home during childhood. Following pilot searches, we excluded terms that identified a large number of irrelevant studies. The final search strategy included phrases such as 'warmth', 'punishment' and 'abuse' (the search terms used are available in the online supplement), and was restricted to studies whose outcomes included symptoms and diagnoses of common (non-psychotic) mental disorders (anxiety and anxiety disorders, depression, dysthymia, suicide, attempted suicide, suicidal ideation or post-traumatic stress disorder (PTSD)). We report the results of studies that investigated associations between relationships in the home during childhood and these common mental health problems in later life.

\section{Study inclusion criteria}

We included studies: (a) with more than 100 participants; (b) in which a measure of relationships in the home during childhood had been made; and (c) at least 10 years prior to the ascertainment of a common, non-psychotic mental disorder, specifically anxiety, depression, dysthymia, suicide, suicidal ideation or PTSD. Where data were collected over an extended period, studies were excluded if the total interval between collection of exposure data and assessment of the last reported outcome data was less than 10 years on average. Some measures of exposure were composite scores obtained by summing a number of variables; these were included if over half of the score derived from items reflecting aspects of relationships in the home.

\section{Procedures}

The search output was downloaded and imported into Procite 5. As there were a large number of titles and abstracts in the original search, a three-stage procedure was adopted. First, all titles and abstracts were reviewed on screen (by R.S.) and we removed papers that clearly did not meet the study criteria. A second (L.M.) and third researcher (C.M.) carried out an independent review of the first 2500 potentially relevant titles and abstracts to check for accuracy. Interrater agreement approached $100 \%$. At the second stage, all titles and abstracts that were potentially suitable for inclusion were checked for eligibility by a second reviewer (J.P.), and full papers were obtained for all those that both reviewers agreed potentially met the inclusion criteria. Fifteen per cent of titles were also screened by one other author (S.W.), which yielded only two disagreements. Any remaining discrepancies were resolved with a further author (S.S.-B.). Where 
abstracts were unavailable, or the paper was retained after screening the abstract, the paper was ordered. The search strategy was intended to be sensitive rather than specific, and many of the articles which passed both of the first two filtering stages did not meet the inclusion criteria for the review.

\section{Data extraction}

For each paper meeting the study criteria, two reviewers extracted data on study population (age, sample size, recruitment methods), variables measured (exposures, outcomes, and confounding factors, including how measured), length and completeness of follow-up, method of statistical analysis and results. Papers reporting analyses on the same cohort were identified. Summaries of characteristics of included studies, covering the size of cohort, start date, age at measurement of exposure and outcome, extent of follow-up and a description of the exposure measure(s) are shown in online Table DS1.

\section{Analysis}

The heterogeneity of included studies meant that meta-analysis was inappropriate. Findings are presented as a narrative synthesis of results from individual cohort studies in tabular form grouped by outcome.

\section{Assessment of methodological quality}

For each study, a quality score was generated with one point for each of the following:

(a) representative sample with adequate follow-up;

(b) validated exposure and outcome measures;

(c) appropriate control for potential confounding;

(d) absence of multiple or post hoc hypothesis testing; and

(e) subjective rating of overall study quality.

\section{Results}

\section{Abstracts identified}

The search yielded 15583 titles, including 145 papers for assessment of the full text. Twenty-three papers based on 16 cohorts were eventually included (Fig. 1). Duration of follow-up ranged from 10 years ${ }^{11}$ to 37 years, ${ }^{12}$ with a median of 22 years.

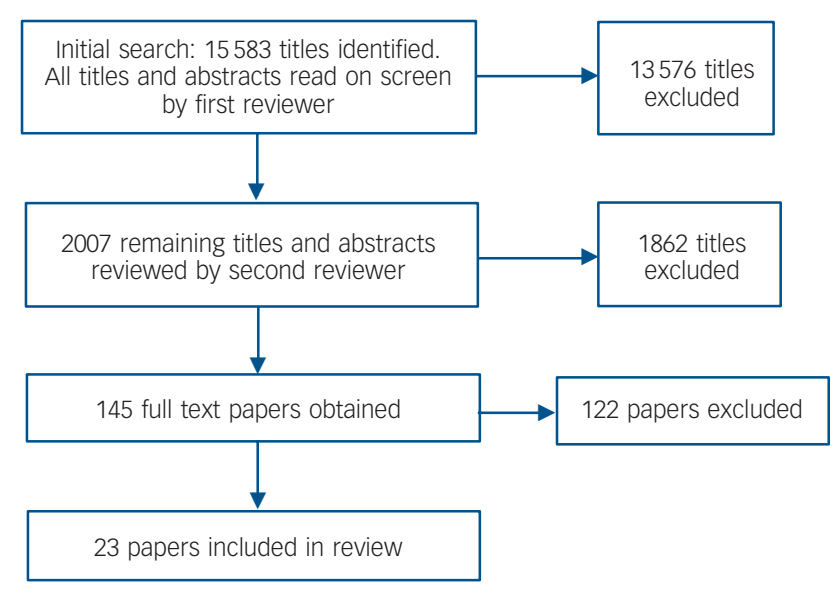

Fig. 1 Flow diagram showing review process.

\section{Depression}

Seventeen studies from 13 cohorts examined the impact of family relationships during childhood and/or adolescence on later depression (online Table DS2). Relationship measures investigated were abuse (physical or sexual) and neglect, ${ }^{13-16}$ lack of family cohesion, ${ }^{11,17}$ parental disharmony, ${ }^{18,19}$ violence in the family, ${ }^{17-20}$ parental disagreement about discipline, ${ }^{21}$ emotional responsiveness/psychological availability of parents, ${ }^{13,22}$ parental rejection, ${ }^{15,18,21}$ lack of parent-child affection; ${ }^{23}$ parent-child discord and affectionless control, ${ }^{11}$ harsh discipline, ${ }^{15,24}$ perceived negative role in the family, ${ }^{20}$ and poor care and mothering. ${ }^{25}$

Heterogeneity was also seen in outcome measures. A clinical diagnosis of depressive disorder was ascertained in nine studies using structured clinical assessments (most commonly the Kiddie Schedule for Affective Disorders and Schizophrenia (KiddieSADS) and Diagnostic Interview Schedule (DIS)), and in one study by means of a semi-structured clinical interview. ${ }^{25}$ In seven studies the outcome was depressive symptoms assessed by questionnaire, completed by a parent or teacher ${ }^{22}$ at follow-up in adolescence and later by the individual themselves. In one study, the outcome was dysthymia, using DSM-III-R criteria. ${ }^{14}$ Whereas most studies reported the presence of depression in the recent past (as either point or period prevalence over the preceding 6-12 months), the latter ascertained lifetime prevalence of dysthymia in a sample whose mean age was 29 years. ${ }^{14}$ No clear trend was found between the type of outcome measure (diagnostic interview $v$. self-report questionnaire) and study findings.

Of 17 studies (based on 5 of 13 cohorts), 8 found unequivocal, statistically significant associations between family relationships and later depression among both men and women; ${ }^{13,20,21,26}$ all of these were rated as high quality. Maltreatment in the form of abuse or neglect was predictive of later depression in five studies, all conducted in different cohorts. In four, results were adjusted for parental socioeconomic status, ${ }^{13,14,16,26}$ and in two for an even wider range of factors including race, ${ }^{16}$ child temperament, harsh parental treatment, family stress and child's exposure to violence, ${ }^{26}$ and family relationship problems. ${ }^{14}$ In addition to associations with childhood abuse, Reinherz et $\mathrm{al}^{20}$ found associations between children's negatively perceived role in the family at age 9 and depression at age 21 (but not at 26), and between family violence and low family cohesion at age 15 and depression by the age of $26{ }^{17}$ The latter analyses were adjusted for a wide range of factors including emotional and behavioural problems in adolescence. Jaffee et $a l^{21}$ found an association between parental disagreement about discipline (between 5 and 9 years) and depression between ages 18 and 26, with an estimated effect size of $0.45(P<0.01)$. Intriguingly, Widom et $a l^{16}$ estimated that abuse or neglect in childhood might bring forward the onset of depression in adolescence by just over $2 \frac{1}{2}$ years.

Three further studies reported positive associations between parent-child relations and later depression in one gender only. These gender interactions were of mixed directionality. Sadowski et $a l^{25}$ found a significant association between poor parental care before the age of 5 and depressive disorder at age 33 among women after adjusting for a range of factors including marital instability. In men, marital instability proved a stronger predictor than parental care which showed no association with depression in men after adjustment. ${ }^{25}$ Lefkowitz \& Tesiny $^{18}$ reported associations between parental rejection and punishment at age 8 and self-reported depression at age 19 among women; however, this relatively low-quality study found no effect for parental disharmony after adjusting for socioeconomic status factors. Leve et $a l^{24}$ found no effect of marital satisfaction on later depression after adjusting for maternal depression, but did report an 
association between harsh discipline at age of 5 and higher scores on Child Behavior Checklist (CBCL) internalising (anxiety and depression) items at age 17 in males.

Two of the studies discussed above also found significant group differences in the context of overall positive results. Lansford et $a l^{26}$ found an interaction with gender such that physical maltreatment at age 5 predicted depression at 17 more strongly in women than men, to a statistically significant degree. Nomura et $a l^{11}$ found an interaction with parental history of depression, showing parent-child discord predicting depression only in the offspring of parents without depression.

Four studies reported associations of note that ceased to reach statistical significance after adjusting for confounding. Roberts \& Bengston $^{23}$ found that an association between perceived quality relationship with one's parents between the ages of 16 and 26 and depression (by self-report questionnaire) 14 years later was confounded on adjusting for gender, age, employment, education, parenthood and income. An association between parental marital satisfaction (assessed up to age 5) and lower scores on anxiety and depression (using CBCL internalising items) at the age of $17^{24}$ was confounded by maternal depression. Similarly, Spence et al ${ }^{19}$ found that an association between 'marital distress' by the age of 5 years and depression at age 14 was confounded by maternal anxiety and depression. Appleyard et $a l^{22}$ (in the same cohort reported on by Egeland ${ }^{13}$ ) found that the association between maternal support to age $3 \frac{1}{2}$ and rates of internalising problems at age 16 was confounded by internalising problems at the time of starting school.

Only two studies found no association between family relationships in childhood and later depression. Thornberry et $a l^{27}$ found no association between maltreatment to the age of 5 and depression at 17 years (and was the sole study to do so). McCord \& Ensminger ${ }^{28}$ found no association between corporal punishment (frequent spanking) to the age of 6 and depression 26-28 years later.

\section{Suicidal ideation and suicide}

Five studies (three of which were rated as high quality) from three cohorts examined the impact of relationships in the home during childhood on suicide, attempted suicide and/or suicidal ideation (Table 1). Egeland ${ }^{13}$ found that both physical abuse and maternal psychological unavailability before the age of 5 predicted attempted suicide by the age of 16 after adjusting for multiple potential confounders. Fergusson \& Lynskey ${ }^{29,30}$ found that maternal psychological unavailability (before age 3 ) was associated with suicide attempts and ideas. Around a third of those who had attempted suicide had mothers whose scores on emotional responsiveness were in the lowest decile - three times the rate of the control group. The effect of maternal unavailability was accounted for by adolescent mental health and/or behavioural problems. ${ }^{30}$ Two quality studies (with low-quality ratings) from another cohort reported an association between self-reported closeness-to-parents in late adolescence and either hospitalisation for mental health problems or suicide over the next 20-30 years. ${ }^{31,32}$ No potential confounding factors were taken into account, but this was a study of men with high socioeconomic status.

\section{Anxiety}

In three studies (from three cohorts), the outcome was best described as 'anxiety.'11,12,15 The results from a further four studies (based on four cohorts) in which the outcome was comorbid anxiety and depression ${ }^{19,26}$ or 'internalising problems ${ }^{22,24}$ were considered with studies of depression (Table 2). Moffitt et al ${ }^{15}$ reported a highly significant association between early maltreatment by age 11 and generalised anxiety disorder at age 32 . Nomura et al ${ }^{11}$ found that poor marital adjustment (but not parent-child discord, low family cohesion or parental affectionless control) at baseline (ages 6-23 years) was associated with anxiety disorder 10 years later, but only if neither parent was depressed at baseline. Overbeek et $a l^{12}$ found no association between the quality of parent-child relationship to age 10 and comorbid anxiety (eight items) and depression (four items) at age 37 (Table 2).

\section{Post-traumatic stress disorder}

Three studies rated as high quality (based on three cohorts) investigated the impact of childhood abuse on later PTSD (Table 3). All three studies found strong associations for both genders, and all three controlled for socioeconomic status. Lansford et $a l^{26}$ found that maltreatment increased the risk of PTSD at 12-year follow-up, as measured by the CBCL $(P<0.01)$ after adjusting for a wide range of potential confounders including child and

Table 1 Suicidal ideation and suicide: outcome measures and confounding factors adjusted for, in included studies

\begin{tabular}{|c|c|c|c|c|}
\hline Cohort & Outcome measure & Factors adjusted for & Quality $^{\mathrm{a}}$ & Results \\
\hline Egeland, $1997^{13}$ & $\begin{array}{l}\text { Attempted suicide, by self-report } \\
\text { (16 years) }\end{array}$ & $\begin{array}{l}\text { Child behaviour, parent-child } \\
\text { relations at } 13 \text { years, infant } \\
\text { temperament, socioeconomic } \\
\text { status }\end{array}$ & $\star * * *$ & $\begin{array}{l}\text { 11-year follow-up: attempted suicide } \\
\text { significantly correlated with psychological } \\
\text { unavailability }(P=0.04) \text { and physical abuse } \\
(P=0.04)\end{array}$ \\
\hline $\begin{array}{l}\text { Fergusson \& } \\
\text { Lynskey, } \\
1995^{29,30}\end{array}$ & $\begin{array}{l}\text { Suicidal ideation and attempted suicide, } \\
\text { ascertained at interview (ages } 15 \text { and } 16 \\
\text { years), including nature and frequency } \\
\text { of thoughts plus any reasons; method, } \\
\text { reasons and medical consequences of } \\
\text { any attempts }\end{array}$ & $\begin{array}{l}\text { For attempts: overall effect of childhood } \\
\text { adversity adjusted for adolescent } \\
\text { psychiatric disorders and adjustment } \\
\text { problems }\end{array}$ & $* * * *$ & $\begin{array}{l}\text { 13-year follow-up: significantly higher } \\
\text { proportion of suicide attempters ( } 27.6 \%) \\
\text { and suicidal ideators (14.2\%) were in the } \\
\text { lowest decile of maternal emotional } \\
\text { responsiveness compared with other } \\
\text { teenagers ( } 9.2 \%)(P<0.005) \\
\text { Association between suicide attempt(s) } \\
\text { and childhood difficulties (including } \\
\text { poverty) explained by adolescent mental } \\
\text { health and behavioural problems }(P>0.30)\end{array}$ \\
\hline $\begin{array}{l}\text { Thomas et al, } \\
1976^{31} \\
\text { Thomas et al, } \\
1979^{32}\end{array}$ & $\begin{array}{l}\text { Suicide or mental illness requiring } \\
\text { hospitalisation, data obtained from death } \\
\text { certificates and hospital records } \\
\text { ( } 35-55 \text { years) }\end{array}$ & - & * & $\begin{array}{l}\text { 14- to } 31 \text {-year follow-up: mean closeness- } \\
\text { to-parents score } 9.20 \text { (s.d.=3.96) for } \\
\text { healthy group } v .5 .91 \text { (s.d.=5.17) for } \\
\text { suicide/mental illness group }(P<0.001)\end{array}$ \\
\hline
\end{tabular}




\begin{tabular}{|c|c|c|c|c|}
\hline Cohort & Outcome measure & Factors adjusted for & Quality $^{\mathrm{a}}$ & Results \\
\hline Moffitt, $2007^{15}$ & $\begin{array}{l}\text { Generalised anxiety disorder using } \\
\text { Diagnostic Interview Schedule } \\
\text { defined as any episode between } \\
\text { ages } 18 \text { and } 32 \text { years }\end{array}$ & Gender & $* * * *$ & $\begin{array}{l}\text { 21-year follow-up: } 14 \% \text { of those with } \\
\text { generalised anxiety disorder had } \\
\text { maltreatment compared with } 3 \% \\
\text { controls; OR }=4.49 \text { ( } 95 \% \mathrm{Cl} 1.5-13.5 \text { ) }\end{array}$ \\
\hline $\begin{array}{l}\text { Nomura } \\
\text { et al, } 2002^{11}\end{array}$ & $\begin{array}{l}\text { Anxiety disorder in past } 8 \text { years, using } \\
\text { Kiddie-SADS interview modified to } \\
\text { include DSM-III-R criteria (6-17 years) } \\
\text { and Adult SADS-Lifetime version } \\
\text { (ages 26-43 years) }\end{array}$ & $\begin{array}{l}\text { Parental depression, sex, age of } \\
\text { off-spring, and socioeconomic } \\
\text { status }\end{array}$ & $* * * *$ & $\begin{array}{l}\text { 10-year follow-up: if either parent } \\
\text { depressed, no effect of relationship } \\
\text { variables on anxiety. If neither parent } \\
\text { depressed, poor marital adjustment } \\
\text { significant (OR }=4.8, P<0.05 \text { ) }\end{array}$ \\
\hline $\begin{array}{l}\text { Overbeek, } \\
2007^{12}\end{array}$ & $\begin{array}{l}\text { Anxiety/depression assessed using } \\
\text { eight anxiety and four depression } \\
\text { items (including Ioneliness) from } \\
\text { Mental Health Inventory }\end{array}$ & $\begin{array}{l}\text { Parent-child conflict, opposite-sex } \\
\text { worries ( } 15-17 \text { years); partner } \\
\text { relationship quality, emotional } \\
\text { maladjustment ( } 25 \text { years) }\end{array}$ & $* * * *$ & $\begin{array}{l}\text { 27-year follow-up: parent-child } \\
\text { relationship quality age } 4-10 \text { years not } \\
\text { significantly related to anxiety/ } \\
\text { depression at age } 37 \text { years ( } r=-0.06 \\
\text { to } 0.05 \text { ) }\end{array}$ \\
\hline
\end{tabular}

\begin{tabular}{|c|c|c|c|c|}
\hline Cohort & Outcome measure & Factors adjusted for & Quality $^{a}$ & Results \\
\hline Egeland, $1997^{13}$ & $\begin{array}{l}\text { PTSD assessed at interview, using } \\
\text { Kiddie-SADS ( } 17.5 \text { years) }\end{array}$ & Socioeconomic status & $* * * *$ & $\begin{array}{l}\text { 17.5-year follow-up: abuse and neglect } \\
\text { associated with PTSD. Those reporting } \\
\text { sexual abuse or maternal psychological } \\
\text { unavailability had higher rates of PTSD } \\
(27 \%) \text { than those without adverse } \\
\text { parenting in pre-school years (12\%) } \\
\text { (P-value not stated) }\end{array}$ \\
\hline $\begin{array}{l}\text { Lansford et al, } \\
2002^{26}\end{array}$ & $\begin{array}{l}\text { PTSD score, derived from CBCL } \\
\text { ratings by mother ( } 16 \text { years) }\end{array}$ & $\begin{array}{l}\text { Socioeconomic status, single-parent } \\
\text { status, family stress, maternal social } \\
\text { support, child exposure to violence, child } \\
\text { temperament, harsh parental treatment } \\
\text { during adolescence and child health }\end{array}$ & $* * * *$ & $\begin{array}{l}\text { 12-year follow-up: maltreated group } \\
\text { mean PTSD score } 7.01(\text { s.e. }=0.75) \mathrm{V} \text {. not } \\
\text { maltreated mean score } 4.34 \text { (s.e. }=0.22) \\
(P<0.01 \text { ) after adjusting for confounders }\end{array}$ \\
\hline Widom, $1999^{33}$ & $\begin{array}{l}\text { Lifetime and current PTSD (DSM-III-R), } \\
\text { using Diagnostic Interview Schedule } \\
\text { (17 years) }\end{array}$ & $\begin{array}{l}\text { Parent arrested, parent had drug } \\
\text { problems, parent on welfare, large family, } \\
\text { behaviour problems, marital status, } \\
\text { parental education, alcohol and/or drug } \\
\text { misuse }\end{array}$ & $* * * \star *$ & $\begin{array}{l}\text { 20-year follow-up: all types of abuse } \\
\text { significantly associated with lifetime and } \\
\text { current PTSD, most at } P<0.001 \text {. } \\
\text { Unadjusted ORs ranged from } 1.7 \text { ( } 95 \% \mathrm{Cl} \\
\text { 1.3-2.3) for neglect predicting lifetime } \\
\text { PTSD to } 2.6(95 \% \mathrm{Cl} 1.5-4.5) \text { for sexual } \\
\text { abuse predicting current PTSD. After } \\
\text { adjusting for confounders, association } \\
\text { between abuse/neglect and PTSD } \\
\text { symptoms (but not diagnosis) remained } \\
\text { statistically significant }(P<0.001 \text { ) }\end{array}$ \\
\hline
\end{tabular}

parent temperament. Widom ${ }^{33}$ showed that court-recorded abuse and/or neglect before the age of 11 were associated with an increased risk of PTSD at age 17, assessed by structured clinical interview after adjusting for child behaviour problems and parent arrests and drug problems. Egeland ${ }^{13}$ found an association (but did not report its statistical significance) between maltreatment before the age of 5 and PTSD at age 17-18, using a different structured clinical interview (Table 3).

No studies reported lower rates of mental health problems among those who experienced abuse, neglect or poor family relationships.

\section{Discussion}

Despite the assumption that childhood maltreatment and poorquality family relationships cause adult psychopathology ${ }^{3-36}$ there have been few prospective cohort studies and fewer still with long-term follow-up. ${ }^{37}$ To the best of our knowledge, this is the first paper to attempt a systematic review of such studies.

The review was restricted to studies of more than 100 participants with more than 10 years follow-up. These inclusion criteria were developed following pilot search to focus the review on studies with most chance of delivering robust, clinically relevant results. It is possible that the review excluded some high-quality small or short-term studies using sophisticated relationship quality measures, alongside the much larger number of poor-quality studies. Prospective ascertainment of the exposure variable (early adversity) long before the outcome occurred is however a strength of all the included studies, precluding the possibility of recall bias.

Included studies varied greatly in design and analysis. They also differed in the aspects of family relationships studied and in their approach to measurement. Some used observation of mother-child interaction, some used detailed interviews, and others employed self-report measures. Studies based on maternal 
report, teacher report and child report methods of collecting outcome data were included.

The most robust findings relate to severe child abuse and neglect. This was predictive of later depression in all but one relatively low-quality study. ${ }^{27}$ All methods of ascertainment of severe abuse and/or neglect (parental interview, observation, child report and court records) were predictive of depression. The results of these studies were independent of socioeconomic factors and, in some cases, of factors (child behavioural problems and family stress) that might have been acting as mediators of the association between abuse and mental health outcomes. Failure by Thornberry et $a l^{27}$ to find significant associations may have been due in part to high rates of depression and undetected abuse in the control group, through the over-sampling of young people at high risk of delinquency and drug misuse. All studies investigating childhood abuse or neglect also found this to be associated with PTSD even after controlling for several potential confounders and effect mediators. These findings are consistent with evidence that childhood sexual abuse (irrespective of the identity of the perpetrator) is associated with most forms of non-psychotic mental illness in adulthood. ${ }^{38}$

Results of studies investigating other forms of dysfunction in parent-child relationships were less clear cut. Our findings are suggestive but not proven. Eight out of ten studies that included measures of aspects of family relationships (including quality of marital relationship) found positive associations with depression. However, in three cases this was restricted to men, women or children of parents without a history of depression and in two studies associations were confounded by other exposures. This inconsistency even extended to studies based on direct observation of parental behaviour. Although one such study based on observations of maternal rejecting behaviour found a clear association with later depression, ${ }^{15}$ another found that this association was restricted to females ${ }^{25}$ and a third reported no association. ${ }^{21}$ A fourth study found no association between observations of poor maternal support and later depression. ${ }^{22}$ By contrast, observed evidence of harsh maternal discipline and/ or emotional unresponsiveness was predictive of suicide attempts in adolescence, ${ }^{13,29,30}$ anxiety ${ }^{15}$ and PTSD. ${ }^{13}$ Although there was some evidence that rejecting attitudes, emotional unavailability, parent-child discord and affectionless control (reported rather than directly observed) increased the risk of depression, anxiety and suicidality, these positive associations were frequently confounded - most often by maternal depression or mental health difficulties in adolescence (both possible examples of overadjustment, see below).

There were relatively few studies of relationship quality and the outcomes of interest in this review - and those that were undertaken used varying exposures - precluding comment on the specificity of effect between these childhood exposures and different adult mental health outcomes. Heterogeneity in the timing of outcomes also precluded examination of either the effect of timing of childhood exposure on adult mental health or whether the effects of childhood maltreatment declined with age in later life. The results in respect of gender differences were also very mixed.

\section{Strengths and weaknesses}

Our comprehensive search strategy initially identified over 15000 abstracts. Our decision to use just three databases is consistent with the approach of other investigators. ${ }^{39}$ We did not hand search journals, since our preliminary search indicated that suitable papers would be widely distributed in journals from a range of disciplines. Given the size of the review, we restricted the review to the most common psychiatric disorders in adult life. Outcomes which were beyond the scope of our study (including psychosis, personality disorders and substance misuse) might also have resulted from adverse early relationships.

Publication bias may have influenced our findings. When data are already collected, less effort is required to conduct studies and less importance may be put on publishing non-significant results. It is also likely that publication bias occurs within single cohorts with positive results being reported and negative ones not coming to light. Among the papers we have included, there were some signs of biased reporting. For example, despite being included in other analyses in the same paper, results for men are not included in the analyses predicting depression in some studies. We have included multiple studies on single cohorts in the review. Although these are both inevitable and valuable, their results cannot be regarded as independent of each other in the same way as multiple studies on different cohorts

Studies included in this review were diverse in methodology, particularly in the ascertainment of exposures and outcomes. Although syndromal classifications suggest that anxiety, depression and PTSD are distinct entities, they share phenomenological and aetiological similarities and commonly co-occur. ${ }^{40}$ In many studies adversity was of a very severe nature, and in several instances primary data were obtained or verified through court or social services records. Even where this was assessed using child and parent self-report, such data could not have been confounded by the child's later mental health given the length of interval between recordings of exposure and outcome. However, these studies did not record duration of relationship disturbance, and it is possible that this may have contributed to heterogeneity of reported associations. The long-term impact of lack of affection is likely to be greater if it is a stable and enduring pattern of relating, and less likely for occasional events.

The other main difficulty in interpretation concerns confounding. Most studies (including all of the higher quality studies) adjusted for potential confounders including socioeconomic status and parental and family characteristics. It was not possible to adjust for all factors (including life events) that might have confounded associations over intervals of 10 years and more, and none of the studies reviewed adjusted for shared genetic risk. Relationship disturbances are associated with many environmental factors, such as lack of educational and employment opportunities and poor social relationships. Studies that did not take account of these confounders may have overestimated the strength of any associations. On the other hand, it can be argued that analyses in some studies were over-adjusted and therefore underestimate risk. Parent-child relationships are a well-recognised cause of behavioural problems in childhood, and behavioural problems are a predictor of depression in later life. Adjustment for childhood behaviour problems in such circumstances will underestimate the effect of parenting on subsequent mental health as some of the effect is likely to be mediated through behaviour problems. Equally, parental mental illness interferes with parenting, and some of its detrimental impact is likely to be mediated through disruptions to parenting. Adjusting for parental mental health in these circumstances could also result in an underestimate of the effect of parenting.

Maltreatment, neglect and other relationship problems may lead to later psychiatric disorder through multiple pathways, including exposure to further abuse and trauma, poor educational attainment, unemployment, poverty, alcohol and drug misuse, and unsatisfactory adult relationships. ${ }^{41}$ Previous research indicates that the effects of childhood adversity are contingent on other risk factors, especially lack of parental care. ${ }^{10}$ Nomura et $a l^{11}$ found that effects of the parent-child relationship varied 
with parental mental health. Genetic predisposition to depression may outweigh effects of exposures such as affectionless control, or may be mediated by the latter. ${ }^{4}$ Conversely, parental depression may be completely confounded by poor parenting given the difficulty of providing secure, affectionate care when suffering from a severe mental illness. As parenting may be amenable to intervention in families where parents suffer mental health problems, it remains important to try and tease out the impact of these different factors.

\section{Implications}

Prospective, long-term cohort studies over periods ranging from 10 to 37 years support the view that parental abuse (physical and sexual abuse, and neglect) in childhood is inextricably linked with common psychiatric disorders in later life. The data in studies relating to abuse are strong enough to suggest a causal relationship. Studies of less severe problems in family relationships such as emotional unresponsiveness, rejection and family discord are suggestive rather than conclusive of causality and more studies are needed. Such problems are far more common than abuse and, if causal, would have a greater impact on the prevalence of adult psychiatric disorder; they may also offer more potential for remediation.

Although the appropriate studies are necessarily time consuming and costly, an increasing number of cohort studies are available for analysis in the public domain. Some of the cohort studies reported in this review would appear to have been underresearched and could provide the basis for future high-quality studies. Elucidating the complex mechanisms linking these exposures and outcomes demands further investigation. Greater support for data curation and for the archiving of existing and future cohorts is needed, as is support for measuring parent-child and parent-parent relationships prospectively. The choice of relationship measures is arguably the most important decision of all, and our findings would suggest that those based on (repeated) independent observation are arguably the gold standard against which all others must be compared. Above all, our results highlight the need for interventions to prevent the evident long-term harm associated with the most dysfunctional parent-child relationships.

Scott Weich, Health Sciences Research Institute, University of Warwick, Coventry; Jacoby Patterson, Research Consultant, Windsor; Richard Shaw, Department of Epidemiology and Public Health, University College London; Sarah Stewart-Brown, Director, Health Sciences Research Institute, Warwick Medical School, University of Warwick Coventry, UK

Correspondence: Scott Weich, Health Sciences Research Institute, Warwick Medical School, Medical School Building, University of Warwick, Coventry CV4 7AL, UK. Email: s.weich@warwick.ac.uk

First received 3 Jul 2007, final revision 19 Aug 2008, accepted 21 Aug 2008

\section{Acknowledgements}

Lesley Morgan and Carole Mockford played an important role in the setting up of this study and the early identification of studies for inclusion. We gratefully acknowledge thei contribution.

\section{References}

1 Rutter M. Connections between child and adult psychopathology. Eur Child Adolesc Psychiatry 1996; 5: 4-7.

2 Harrington R. Causal processes in development and psychopathology. Br J Psychiatry 2001; 179: 93-4.
3 Lyons-Ruth K. Attachment relationships among children with aggressive behavior: the role of disorganised early attachment patterns. J Consult Clin Psychol 1996; 64: 64-73.

4 Kendler KS, Gardner CO, Prescott CA. Toward a comprehensive developmental model for major depression in women. Am J Psychiatry 2002; 159: $1133-45$.

5 Rutter M. How the environment affects mental health. Br J Psychiatry 2005; 186: 4-6.

6 Flemming AS, O'Day DH, Kraemer GW. Neurobiology of mother-infant interactions: experience and central nervous system platicity acros development and generations. Neurosci Behavioral Rev 1999; 23: 673-85.

7 Shonkoff JPE, Phillips DA. From Neurons to Neighborhoods: The Science of Early Child Development. National Academy Press, 2000.

8 Parker G, Hadzi-Pavlovic, Greenwald S, Weissman M. Low parental care as a risk factor to lifetime depression in a community sample. J Affect Disord 1995; 33: 173-80.

9 Rodgers B. Reported parental behaviour and adult affective symptoms. 1. Associations and moderating factors. Psychol Med 1996; 26: 51-61.

10 Hill J, Pickles A, Burnside E, Byatt M, Rollinson L, Davis R, et al. Child sexual abuse, poor parental care and adult depression: evidence for different mechanisms. Br J Psychiatry 2001; 179: 104-9.

11 Nomura Y, Wickramaratne PJ, Warner V, Mufson L, Weissman MM. Family discord, parental depression, and psychopathology in offspring: ten-year follow-up. J Am Acad Child Adolesc Psychiatry 2002; 41: 402-9.

12 Overbeek G, Stattin H, Vermulst A, Ha T, Engels RCME. Parent-child relationships, partner relationships, and emotional adjustment: a brith-tomaturity prospective study. Dev Psychol 2007; 43: 429-37.

13 Egeland B. Mediators of the effects of child maltreatment on developmental adaptation in adolescence. In Developmental Perspectives on Trauma: Theory, Research, and Intervention (eds Cicchetti D \& Toth SL). University of Rochester, 1997.

14 Horwitz AV, Widom CS, McLaughlin J, White HR. The impact of childhood abuse and neglect on adult mental health: a prospective study. $J$ Health Soc Behav 2001; 42: 184-201.

15 Moffitt TE, Caspi A, Harrington H, Milne BJ, Melchior M, Goldberg D, et al. Generalized anxiety disorder and depression: chidlhood risk factors in a birth cohort followed to age 32. Psychol Med 2007; 37: 441-52.

16 Widom CS, DuMont K, Czaja SJ. A prospective investigation of major depressive disorder and comorbidity in abused and neglected children grown up. Arch Gen Psychiatry 2007; 64: 49-56.

17 Reinherz HZ, Paradis AD, Giaconia RM, Stashwick CK, Fitzmaurice G. Childhood and adolescent predictors of major depression in the transition to adulthood. Am J Psychiatry 2003; 160: 2141-7.

18 Lefkowitz MM, Tesiny EP. Rejection and depression: prospective and contemporaneous analyses. Dev Psychol 1984; 20: 776-85.

19 Spence SH, Najman JM, Bor W, O'Callaghan MJ, Williams GM. Maternal anxiety and depression, poverty and marital relationship factors during early childhod as predictors of anxiety and depressive symptoms in adolescence. J Child Psychol Psychiatry 2002; 43: 457-69.

20 Reinherz HZ, Giaconia RM, Hauf AM, Wasserman MS, Silverman AB. Major depression in the transition to adulthood: risks and impairments. J Abnorm Psychol 1999; 108: 500-10.

21 Jaffee SR, Moffitt TE, Caspi A, Fombonne E, Poulton R, Martin J. Differences in early childhood risk factors for juvenile-onset and adult-onset depression. Arch Gen Psychiatry 2002; 59: 215-22.

22 Appleyard K, Egeland B, Sroufe LA. Direct social support for young high risk children: relations with behavioural and emotional outcomes across time. J Abnorm Psychol 2007; 35: 443-57.

23 Roberts RE, Bengston VL. Relationships with parents, self-esteem, and psychological well-being in young adulthood. Soc Psychol Q 1993; 56: 263-77.

24 Leve LD, Kim HK, Pears KC. Childhood temperament and family environment as predictors of internalizing and externalizing trajectories from ages 5 to 17 . J Abnorm Child Psychol 2005; 33: 505-20.

25 Sadowski H, Ugarte B, Kolvin I, Kaplan C, Barnes J. Early life family disadvantages and major depression in adulthood. Br J Psychiatry 1999; 174: 112-20.

26 Lansford JE, Dodge KA, Pettit GS, Bates JE, Crozier J, Kaplow J. A 12-year prospective study of the long-term effects of early child physical maltreatment on psychological, behavioral, and academic problems in adolescence. Arch Pediatr Adolesc Med 2002; 156: 824-30.

27 Thornberry TP, Ireland TO, Smith CA. The importance of timing: the varying impact of childhood and adolescent maltreatment on multiple problem outcomes. Dev Psychopathol 2001; 13: 957-79. 
28 McCord J, Ensminger ME. Multiple risks and comorbidity in an AfricanAmerican population. Crim Behav Ment Health 1997; 7: 339-52.

29 Fergusson DM, Lynskey MT. Suicide attempts and suicidal ideation in a birth cohort of 16-year-old New Zealanders. J Am Acad Child Adolesc Psychiatry 1995; 34: 1308-17.

30 Fergusson DM, Lynskey MT. Childhood circumstances, adolescent adjustment, and suicide attempts in a New Zealand birth cohort. J Am Acad Child Adolesc Psychiatry 1995; 34: 612-22.

31 Thomas CB. Precursors of premature disease and death. The predictive potential of habits and family attitudes. Ann Intern Med 1976; 85: 653-8.

32 Thomas CB, Duszynski KR, Shaffer JW. Family attitudes reported in youth as potential predictors of cancer. Psychosom Med 1979; 41: 287-302.

33 Widom CS. Posttraumatic stress disorder in abused and neglected children grown up. Am J Psychiatry 1999; 156: 1223-9.

34 Mullen PE, Romans-Clarkson SE, Walton VA, Herbison GP. A study of the impact of sexual and physical abuse on women's mental health. Lancet 1988; 1: 841-5.

35 Mullen PE, Martin JL, Anderson JC, Romans SE, Herbison GP. Childhood sexual abuse and mental health in adult life. Br J Psychiatry 1993; 163: 721-32.
36 MacMillan $\mathrm{HL}$, Fleming JE, Streiner $\mathrm{DL}$, Lin $\mathrm{E}$, Boyle $\mathrm{MH}$, Jamieson $\mathrm{E}$, et al. Childhood abuse and lifetime psychopathology in a community sample. Am J Psychiatry 2001; 158: 1878-83.

37 Mullen PE. Invited commentary on: Abusive experiences and psychiatric morbidity in women primary care attenders. Br J Psychiatry 2003; 183: $340-1$.

38 Spataro J, Mullen PE, Burgess PM, Wells DL, Moss SA. Impact of child sexual abuse on mental health. Prospective study in males and females. Br J Psychiatry 2004; 184: 416-21.

39 Frank DA, Augustyn M, Knight WG, Pell T, Zuckerman B. Growth, development, and behavior in early childhood following prenatal cocaine exposure: a systematic review. JAMA 2001; 285: 1613-25.

40 Vollebergh WA, ledema J, Bijl RV, de Graaf R, Ormel J. The structure and stability of common mental disorders. Arch Gen Psychiatry 2001; 58 597-603.

41 Gladstone GL, Parker GB, Mitchell PB, Malhi GS, Wilhelm K, Austin MP. Implications of childhood trauma for depressed women: an analysis of pathways from childhood sexual abuse to deliberate self-harm and revictimisation. Am J Psychiatry 2004; 161: 1417-25.

\title{
Poems by doctors
}

\section{Brief reflection on the word Pain}

\section{Miroslav Holub}

\author{
Wittgenstein says: the words "It hurts" have replaced \\ tears and cries of pain. The word "Pain" \\ does not describe the expression of pain but replaces it. \\ Thus it creates a new behaviour pattern \\ in the case of pain. \\ The word enters between us and the pain \\ like a pretence of silence. \\ It is a silencing. It is a needle \\ unpicking the stitch \\ between blood and clay. \\ The word is the first small step \\ to freedom \\ from oneself. \\ In case others \\ are present.
}

Holub, M. (2006) Brief reflection on the word Pain. In Poems Before and After (transl. I. Milna \& T. Milna). Bloodaxe Books.

Miroslav Holub (1923-1998) was born in Pilsen, western Bohemia, He studied medicine at Charles University in Prague and trained as an immunologist at the Microbiological Institute of the Czechoslovak Academy of Science. He was a successful scientist but is best known for his poetry. His recognition followed the publication in 1967 of Selected Poems as part of Penguin's series on modern European poets. His poetry was proscribed in Czechoslovakia between 1970 and 1980. Another of Holub's poems was published in the August 2008 issue of the Journal.

Researched by Femi Oyebode. 